\title{
Kepribadian dan Ikigai Tokoh Utama Pelaku Pembunuhan dalam Film Kokuhaku
}

\author{
Diani Ratna Pungkasari'), Yusida Lusiana ${ }^{2)}$, Muammar Kadafi ${ }^{\text {) }}$ \\ Program Studi Sastra Jepang, FIB, Universitas Jenderal Soedirman \\ Purwokerto-Indonesia ${ }^{123}$ \\ ${ }_{1}^{1}$ diani.pungkasari@mhs.unsoed.ac.id] 2[yusida.lusiana@unsoed.ac.id] \\ 3 [muammar.kadafi@unsoed.ac.id]
}

\begin{abstract}
Abstrak
Penelitian ini bertujuan untuk mengkaji hubungan antara kepribadian tokoh dan konsep motivasi khas Jepang ikigai pada tokoh pelaku pembunuhan dalam film Kokuhaku yang bernama Yuko Moriguchi, Shuya Watanabe dan Naoki Shimomura. Metode yang digunakan adalah metode deskriptif kualitatif dengan pendekatan psikologi sastra. Teori kepribadian yang digunakan adalah teori tipologi kepribadian Jung, dan konsep ikigai pada penelitian ini menggunakan konsep dari Hasegawa. Hasil penelitian ini menunjukkan bahwa tokoh Yuko Moriguchi mempunya kepribadian ekstrovert-berpikir serta ikigai-nya adalah anaknya, kemudian Shuya Watanabe memiliki kepribadian introvert-berpikir dengan ikigai mendapatkan pengakuan, dan Naoki Shimomura memiliki kepribadian introvert-berpikir dengan ikigai yang dimiliki yaitu mendapatkan pengakuan. Kesimpulan yang dapat diambil dari penelitian ini adalah bahwa kepribadian dan ikigai seseorang saling mempengaruhi satu sama lain khususnya pada perilaku yang dilakukan.
\end{abstract}

Kata kunci: Pembunuhan, Psikologi Sastra, Tipologi kepribadian Jung, Ikigai

\begin{abstract}
This study aims to examine the relation between the character's personality and the Japanese motivational concept of ikigai on the murderers of the Kokuhaku's movie, Yuko Moriguchi, Shuya Watanabe, and Naoki Shimomura. The method used in this study is a qualitative descriptive method with a literary psychology approach. The personality theory used is Jung's theory of personality typology, and the concept of ikigai in this study uses the concept by Hasegawa. The results of this study indicate that Yuko Moriguchi has an extroverted-thinking personality and her ikigai is her daughter, then Shuya Watanabe has an introverted-thinking personality with gaining recognition as his ikigai, and Naoki Shimomura has an introverted-thinking personality and his ikigai is gaining recognition. The conclusion that can be drawn from this research is that a person's personality and ikigai influence each other, especially in their behavior.
\end{abstract}

Keywords: Murder, Literary Psychology, Carl G. Jung's Typology of Personality, Ikigai

\section{Pendahuluan}

Pembunuhan adalah perbuatan yang menghilangkan atau mencabut nyawa seseorang (Zuhaili, 1984: 2). Aksi pembunuhan yang terjadi dari masa ke masa selalu dilatarbelakangi oleh motivasi yang berbeda satu sama lain. Misalnya untuk menyelamatkan nyawa sendiri, iri hati, balas dendam, ingin mendapatkan pengakuan dari orang lain, dan lain sebagainya. Pengertian motivasi dikatakan oleh Rivai (2006: 455) 
adalah suatu rangkaian nilai-nilai yang dapat mempengaruhi setiap individu untuk mencapai hal spesifik tertentu sesuai dengan tujuannya.

Bangsa Jepang merupakan salah satu bangsa yang memiliki filosofi khas terkait dengan motivasi tentang kehidupan, filosofi tersebut adalah ikigai [生き甲斐]. Ikigai berasal dari bahasa Jepang yang memiliki arti “tujuan hidup” (Musman, 2020: 16). Ikigai setiap orang memang berbeda-beda, tetapi satu hal yang sama adalah bahwa setiap orang sama-sama mencari sebuah makna dari kehidupan. Tetapi tidak menutup kemungkinan bahwa akan menimbulkan stres dan kecemasan pada diri orang tersebut yang akhirnya dapat membuat individu melakukan perbuatan agresi yaitu dalam hal ini adalah membunuh sesama manusia.

Saking maraknya peristiwa pembunuhan sesama manusia, banyak penulis naskah film yang menjadikannya sebagai inspirasi untuk membuat film dengan latar kisah pembunuhan. Menurut Irawanto (dalam Sobur 2003: 127), film selalu merekam realitas yang tumbuh dan berkembang dalam masyarakat yang kemudian diproyeksikan ke atas layar. Dengan itu, film dimaknai sebagai cerminan atau representasi kehidupan. Kristanto (2004: 3) juga mengatakan bahwa film dapat menjadi media pembelajaran bagi khalayak. Berdasarkan penjelasan tersebut, film dapat membuat orang memahami perilaku masyarakat dari suatu tempat tanpa harus berada di tempat tersebut. Pada penelitian ini, akan dijabar mengenai karakter tokoh pembunuhan dalam film Kokuhaku serta motivasi mengapa mereka melakukan pembunuhan tersebut dilihat dari ikigai yang mereka miliki. Film Kokuhaku merupakan sebuah film Jepang yang dibuat tahun 2010 dan disutradarai oleh Tetsuya Nakashima. Film ini merupakan adaptasi dari sebuah novel dengan judul yang sama pada tahun 2008 yang dibuat oleh seorang ibu rumah tangga bernama Kanae Minato.

Ikigai berasal dari bahasa Jepang yang memiliki arti "tujuan hidup" (Musman, 2020: 16). Mitsuhashi dalam bukunya (2018: 7) mengatakan bahwa Ikigai dibentuk dari dua suku kata atau kanji, yaitu $i k i$ [生き] yang berarti kehidupan, dan gai [甲斐] yang berarti nilai. Jadi, ikigai adalah nilai dari kehidupan, kebahagiaan di dalam hidup. Singkatnya, ikigai adalah adalah alasan yang membuat bangun di pagi hari. Setelah diketahui mengenai kepribadian dan ikigai dari masing-masing tokoh maka akan dicari tahu mengenai hubungan antara kepribadian dan ikigai tokoh pelaku pembunuhan. 
Ketiga tokoh dalam film Kokuhaku melakukan pembunuhan dengan latar belakang yang berbeda-beda. Berdasarkan pernyataan tersebut, penulis dapat membuat pertanyaan penelitian sebagai berikut:

1. Bagaimana tipe kepribadian ketiga tokoh pelaku pembunuhan film Kokuhaku berdasarkan teori tipologi kepribadian Jung?

2. Bagaimana ikigai ketiga tokoh pelaku pembunuhan di film Kokuhaku?

3. Bagaimana hubungan antara kepribadian dan ikigai tokoh pelaku pembunuhan?

Penelitian ini bertujuan untuk mengkaji hubungan antara kepribadian tokoh dan konsep motivasi khas Jepang ikigai pada tokoh pelaku pembunuhan dalam film Kokuhaku. Teori kepribadian menggunakan teori tipologi kepribadian Carl G. Jung dan dan konsep ikigai pada penelitian ini menggunakan konsep dari Akihiro Hasegawa. Agar selanjutnya diketahui bagaimana jenis kepribadian dan ikigai seseorang yang cenderung melakukan pembunuhan.

\section{Metode dan Teori}

\subsection{Metode Penelitian}

Jenis penelitian ini adalah penelitian deskriptif kualitatif. Merupakan penelitian yang mengumpulkan dan menganalisis data penelitian dengan latar ilmiah dan tidak berhubungan dengan angka. Data yang digunakan dalam penelitian ini adalah audio visual yang berhubungan dengan kepribadian dan ikgaii tokoh. dengan sumber data yang dipakai oleh penulis yaitu film Kokuhaku yang disutradarai oleh Tetsuya Nakashima, yang merupakan film drama Jepang tahun 2010. Untuk mengumpulkan data yang digunakan, dalam penelitian ini penulis menggunakan teknik simak dan teknik catat. Teknik analisis data yang digunakan dalam penelitian ini adalah analisis kualitatif, seperti yang dikatakan oleh Miles dan Huberman (1992: 16) analisis kualitatif terdiri dari tiga alur yaitu pengumpulan data, reduksi data, penyajian data dan penarikan kesimpulan.

\subsection{Teori}

Kepribadian tokoh pelaku pembunuhan dalam film Kokuhaku, digunakan teori tipologi kepribadian Jung. Jung (dalam Naisaban 2003: 3-4) merumuskan tipe kepribadian manusia dengan istilah extraversion (ekstrovert) dan introversion (introvert), serta mengemukakan empat fungsi kepribadian manusia, yaitu fungsi thinking (berpikir), feeling (perasa), sensing (pengindera), dan intution (intuitif). Selanjutnya untuk mencari 
mengenai ikigai para tokoh melakukan pembunuhan, penulis akan menggunakan konsep ikigai sebagai filosofi kehidupan bangsa Jepang mengenai motivasi tujuan hidup.

\section{Kajian Pustaka}

Pada penelitian yang dilakukan oleh Kono dan Walker (2020) yang berjudul Theorizing the interpersonal aspect of ikigai ('life worth living') among Japanese university students, mengatakan bahwa ikigai bisa menimbulkan hal negatif yaitu stres karena tuntutan untuk bekerja sama dengan orang lain atau interaksi sosial. Berdasarkan penjelasan tersebut, dapat dikatakan bahwa kebahagiaan, keberanian, harapan, adalah yang membuat hidup seseorang dapat merasakan kepuasan atau ikigai.

\section{Hasil dan Pembahasan}

Pada bagian ini, penulis akan meneliti kepribadian tiga tokoh pelaku pembunuhan dalam film Kokuhaku yaitu Yuko Moriguchi, Shuya Watanabe, dan Naoki Shimomura menggunakan tipologi kepribadian Jung (1921).

\subsection{Analisis Kepribadian Yuko Moriguchi}

\subsubsection{Sikap}

Seperti individu pada umumnya, Yuko mempunyai dua sikap dalam kepribadiannya yaitu Ekstrovert dan Introvert.

\section{a. Ekstrovert}

Beberapa adegan di bawah ini memperlihatkan sikap ekstrovert yang dimiliki oleh Yuko.

1. Orang ekstrovert mempunyai kecenderungan ke dunia luar yang sangat kuat, bahkan bisa lupa memperhatikan dan mengurus dirinya sendiri (Naisaban, 2003: 15).

Tokoh Yuko memiliki ciri-ciri ekstrovert ini dilihat dari adegan di bawah.

\section{女子生徒：何で結婚しないの?}

悠子：たとえ生まれた子が感染していなくても、父親が感染者だと分かれ ば、世間の差別は免れません。

男子生徒：差別をするほうは悪いんじゃ？

悠子：光れは将来、父親がいないことょり、ずっと子供を苦しめる、光れ が彼の判

(Kokuhaku 2010, 00:07:49-00:08:09)

Joshiseito : Nanide kekkon shinaino? 
Yūko : :Tatoe umareta ko ga kansen shite inakutemo, chichioyaga kansen-shada to wakareba, seken no sabetsu wa manugaremasen.

Danshi seito : Sabetsu o suru hō wa warui $n$ ja?

Yūko : Sorewashōrai, chichioyaga inai koto yori, zutto kodomo o kurushimeru, sore ga kare no han

Siswi : Mengapa Anda tidak menikah?

Yuko : Walaupun si anak tidak tertular, jika ada orang yang tahu bahwa ayahnya mengidap HIV maka si anak akan mendapatkan diskriminasi.

Siswa : Akankah seburukitu?

Yuko : Itu akan jadi lebih buruk dari pada tidak mempunyai ayah. Itu adalah keputusan yang kami sepakati.

Yuko mempunyai 1 orang anak bernama Manami yang menjadi korban pembunuhan pada film Kokuhaku ini. Berdasarkan dialog antara Yuko dan muridnya di atas, dapat dilihat bahwa Yuko sangat menyayangi Manami hingga dirinya menentukan jalan hidupnya berdasarkan kesejahteraan hidup Manami. Yuko rela tidak menikahi ayah Manami yang terkena HIV karena takut jika teman-temannya mengetahui ayahnya mengidap penyakit HIV, maka Manami akan menjadi korban bully dan didiskriminasi. Tindakannya itu memperlihatkan bahwa Yuko lebih memperhatikan orang lain daripada memperhatikan hidupnya sendiri yang akan mempunyai seorang anak tanpa adanya seorang suami.

2. Menurut Jung (Naisaban 2003: 15) perilaku ekstrovert extreme kadang mengorbankan tanpa sengaja subjek atau orang lain supaya memenuhi apa yang dilihatnya sebagai tuntutan objektif, ia tenggelam ke dalam objek dan kehilangan diri.

悠子：寺田先生、しばらく学校をお休みになる乥うです。下村くんがあんな ことになってしまって ...

美月：だってあれは、直くんがああなったのはウェルテル ...

悠子：わたしのせいです。寺田先生とはこうして時々会ってました。とても 熱心で、単純で、熱烈な桜宮信者。だからなくなった愛美の父親は桜宮 だと彼に告白しました。彼を取り込み、彼を利用して、あの 2 人を追い 詰めるために

(Kokuhaku 2010, 01:18:50-01:19:29)

Yūko : Terada sensei, shibaraku gakkōo o yasumi ni naru sōdesu. Shimomura-kun ga an'na koto ni natte shimatte...

Mizuki: Datte are wa, Nao-kun ga ānatta no wa u $\sim$ eruteru...

Yūko : Watashi no seidesu. Terada sensei to wa kōshite tokidoki attemashita. Totemo nesshinde, tanjun de, netsuretsuna Sakuramiya shinja.Dakara nakunatta Manami 
no chichioya wa Sakuramiyada to kare ni kokuhaku shimashita. Kare o torikomi, kare o riyō shite, ano 2-ri o oitsumeru tame ni

Yuko : Sepertinya Tereda sensei tidak akan mengajar untuk beberapa waktu. Dia merasa bersalah pada Shimomura-kun...

Mizuki : Nao-kun menjadi seperti itu karena salah Werther...

Yuko : Itu adalah salahku. Aku sering bertemu dengan Tereda sensei. Dia sangat antusias dengan pekerjaannya, sangat baik hati. Dia penggemar berat Sakuramiya. Jadi aku memberitahunya bahwa Sakuramiya adalah ayah Manami. Aku memanfaatkannya untuk membuat kedua anak itu menderita.

Yuko mengetahui bahwa Werther sangat menyukai Sakuramiya yang mana adalah ayah dari Manami. Karena hal tersebut, Yuko memanfaatkan hal tersebut untuk membalaskan dendamnya kepada dua muridnya yang telah membunuh Manami. Yuko mengatakan kepada Werther bahwa Sakuramiya adalah anak Manami, dengan begitu Werther akan mengikuti apapun yang Yuko katakan, tanpa mengetahui bahwa maksudnya adalah untuk membuat Shuya dan Naoki menderita. Pada film Kokuhaku ini, Werther tidak mengetahui akan latar belakang yang terjadi diantara Yuko, Shuya dan Naoki. Hal itu semakin dimanfaatkan oleh Yuko, dan caranya tersebut telah berhasil. Yuko memanfaatkan Werther untuk memenuhi apa yang dilihatnya sebagai tuntutan objektif, dan hal ini merupakan ciri-ciri bahwa seorang individu merupakan seseorang yang mempunyai perilaku ekstrovert ekstrem.

\section{b. Introvert}

Data di bawah ini mencerminkan sikap Introvert yang dimiliki oleh tokoh Yuko Moriguchi.

1. Orang yang memiliki sikap introvert menganggap bahwa tempat tinggalnya adalah yang teraman dan teman pribadinya adalah yang terbaik, maka dari itu mereka cenderung tampak sebagai orang yang egois (Naisaban 2003: 19). Dalam adegan berikut ini, tokoh Yuko memperlihatkan keegoisannya.

悠子 : 何より私は、あなた方の言葉を 100 \%信じたりできません。 女子生徒：先生は私たちを信用していませんか。

悠子：ええ、あなた方はう光をつくのが、実に上手ですから。 (Kokuhaku 2010,00:04:33 - 00:05:19)

Yūko : Naniyori watashi wa, anatagata no kotoba o 100-pāsento shinji tari dekimasen. Joshi seito: Sensei wa watashitachi o shin'yō shite imasen ka.

Yūko : Ee, anatagata wa uso o tsuku no ga, jitsuni jōzudesukara. 
Yuko : Terus terang saja ibu tidak pernah mempercayai 100\% apa yang kalian katakan.

Siswa : Jadi sensei tidak mempercayai kami?

Yuko : Tidak, karena kalian sangat pandai berbohong.

Sebagai seorang guru sudah sepatutnya memahami keadaan muridnya. Tetapi, Yuko tidak melakukan hal tersebut karena tidak ingin ada hal burukyang menimpanya. Menjadi seorang guru sudah pasti mempunyai risiko yang akan ditanggung, tetapi dalam dialog di atas, Yuko terkesan tidak mahu menanggung risiko tersebut. Ia lebih memilih untuk memikirkan dan melindungi dirinya sendiri. Padahal belum tentu muridnya tersebut mempunyai intensi yang buruk kepadanya, namun Yuko tetap memilih untuk melindungi dirinya sendiri. Hal ini sangat memperlihatkan bahwa tokoh Yuko mempunyai keegoisan yang mencerminkan sikap introvert.

\subsubsection{Fungsi}

Yuko Moriguchi dalam film Kokuhaku memperlihatkan keempat fungsi jiwa yang dimilikinya, berikut analisis mengenai empat fungsi jiwa tersebut.

\section{a. Berpikir}

Data berikut ini memperlihatkan fungsi berpikir yang dimiliki oleh tokoh Yuko Moriguchi.

1. Orang yang memiliki fungsi berpikir umumnya bekerja atas dasar logika, objektivitas, dan bermental analitis (Naisaban 2003: 27). Adegan berikut ini memperlihatkan ciri tersebut pada Yuko.

悠子：ただひとつ、愛美が死んだのはポシェットのせいではありません。私は このポシェットを細かく調べました。たとえ四歳の子でも、心臓を止め ることなどまず不可能な、お粗末な代物でした。試してみます？愛美は ただ気を失っていただけなんです。B がプールに放り投げた事による水 死。これが紛れも無い愛美の死因です。

(Kokuhaku 2010,00:27:22 - 00:27:58)

Yūko : Tada hitotsu, Manami ga shinda no wa poshetto no seide wa arimasen. Watashi wa kono poshetto o komakaku shirabemashita. Tatoe shi-sai no ko demo, shinzō o tomeru koto nado mazu fukanōna, o somatsuna shiromonodeshita. Tameshite mimasu? Manami wa tada ki o ushinatte ita dakena ndesu. B ga pūru ni hōri nageta koto ni yoru suishi. Kore ga magire mo nai Manami no shiindesu.

Yuko : Ada satu hal lagi, penyebab kematian Manami bukanlah tas kecil itu. Aku sudah memeriksa tas ini. Kekuatannya tidak akan cukup untuk menghentikan jantung 
anak berumur 4 tahun. Ini adalah prduk gagal. Kamu mau mencobanya? Manami sebenarnya hanya pingsan. Aku yakin Manami meninggal karena tenggelam setelah siswa B melemparnya ke dalam kolam renang.

Adegan di atas adalah ketik Yuko tengah menceritakan kronologis kematian Manami kepada muridnya. Sebelumnya, Manami dikatakan meninggal karena kecelakaan yaitu terjatuh di kolam renang. Sebagian banyak orang mungkin akan langsung mempercayai hal tersebut karena itu merupakan pernyataan yang dilontarkan oleh polisi. Tetapi tidak dengan Yuko. Yuko tidak mau tinggal diam dan mencari tahu mengapa anak semata wayangnya bisa meninggal di kolam renang sekolah. Akhirnya ia menemukan tas Manami yang ada di sekitar kolam, dan mengetahui bahwa ada setrum di dalam tas itu. Kemudian ia menyimpulkan bahwa kematian Manami bukanlah sebuah kecelakaan, melainkan pembunuhan. Pada adegan ini sangat terlihat bahwa Yuko merupakan tokoh yang sangat analitik.

2. Orang yang berfungsi berpikir adalah orang yang mengatur segala sesuatu dalam keadaan yang teratur (Naisaban 2003: 27). Mereka dapat mengatur segalanya dengan rinci. Berikut adegan dari tokoh Yuko yang mencerminkan hal ini.

悠子：まあ、とにかく。あなたから預かったプレゼント、あなたの発明品をお 渡しして、私はすぐに御暇しました。素敵なお母様。だからあなたが スイッチを押さないことを新っていました。でもあなたは押してしまっ た。私にも聞こえましたよ。大切なものが消える音が「パチン」じゃな く「ドッカーン」って

修哉：やめろ！！！

(Kokuhaku 2010, 01:35:49-01:37:22)

Yūko : Ma a, tonikaku. Anata kara azukatta purezento, anata no hatsumei-hin o o watashi shite, watashi wa sugu ni o hima shimashita. Sutekina okāsama. Dakara anata ga suitchi o osanai koto o inotte imashita. Demo anata wa oshite shimatta. Watashi ni mo kikoemashita yo. Taisetsuna mono ga kieru oto ga 'pachin' janaku 'dokkān'tte

Shūya : Yamero!!!

Yuko : Aku memberikannya hadiah kecilmu. Aku meninggalkan bom-mu, dan aku bergegas pergi. Ibumu sangat baik, aku berharap kau tidak menekan tombol itu. Tapi kau, malah menekannya. Aku juga mendengar suara itu, suara kehilangan sesuatu yang berharga. Bukan "Ting", tapi "Duar!!"

Shuya : Hentikan!! 
Yuko mengetahui bahwa Shuya akan tetap menekan tombol yang menjadi remot untuk bom rakitannya. Oleh karena itu, sebelumnya ia telah membawa bomnya ke ruang kerja ibunya, sehingga bomnya meledak di ruangan itu sekaligus meledakkan ibu Shuya. Ia membuat seolah-olah Shuy a sendirilah yang membunuh ibunya, agar Shuya semakin terpuruk. Hal ini menunjukkan bagaimana tokoh Yuko merupakan orang yang mengatur segala sesuatu dengan teratur, yang mana menunjukkan fungsi berpikirnya.

\subsection{Analisis Kepribadian Shuya Watanabe}

\subsubsection{Sikap}

Dalam film Kokuhaku, tokoh Shuya menunjukkan kedua tipe sikapjiwa menurut Jung, yaitu ekstrovert dan introvert.

\section{a. Ekstrovert}

Data di bawah akan memperlihatkan sikap ekstrovert yang dimiliki oleh Shuya pada film Kokuhaku.

1. Orang dengan sikap ekstrovert sangat berani. Kadang ia mengarah ke sikap ekstrem sampai pada tahap risiko (Naisaban 2003: 14). Berikut merupakan adegan saat Shuya melakukan perbuatan berani yang eksrem.

修哉：読み終わると同時にスイッチを押す。木っ端みじんに吹っ飛ぶ僕と僕の 周りのバカたち。

(Kokuhaku 2010,01:04:47-01:04:55)

Shuya : Aku akan meledakkannya setelah selesai berpidato. Meledakan diriku bersama orang-orang bodoh itu hingga hancur tak tersisa.

Perkataan yang dikatakan Shuya di atas adalah ketika dirinya merencanakan dan membayangkan pengeboman sekolahnya. Ia berencana untuk bunuh diri dengan bom buatannya sekaligus membunuh orang-orang yang ada di sekolah. Semua itu dilakukan hanya agar mendapatkan pengakuan dari sang ibu.

Jika dilihat dari hal tersebut, tokoh Shuya sangat memperlihatkan keberaniannya. Tetapi caranya sangatlah ekstrim sampai-sampai bisa menimbulkan risiko yang besar. Hanya karena ingin mendapatkan pengakuan dari ibunya, ia berencana untuk membunuh warga sekolah, yang bahkan tidak mengetahui apa-apa tentang masalahnya. Hal ini sangat 
mencerminkan orang dengan sikap ekstrovert yang berani dan cenderung melakukan perbuatan ekstrim yang berisiko.

\section{b. Introvert}

Tokoh Shuya beberapa kali memperlihatkan sikap introvert-nya dalam film Kokuhaku, berikut merupakan data yang diperoleh penulis.

1. Naisaban mengatakan (2003:18) seorang introvert adalah orang yang cenderung menarik diri dari kontak sosial. Pada adegan berikut, tokoh Shuya terlihat menarik diri dari kontak sosial.

Gambar 4.2.1

Scene Film Kokuhaku Ketika Shuya Menarik Diri dari Kontak Sosial

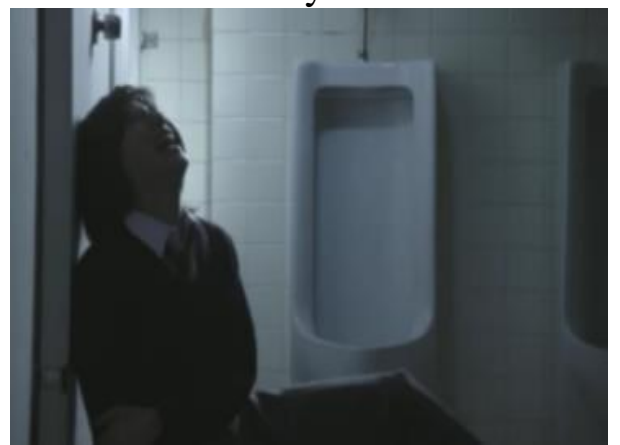

Sumber: Kokuhaku 2010, 01:12:14

悠子 : 私は 2 人が飲んだ牛乳にあるものを混ぜました。桜宮正義先生の血液 です。

修哉：最高だよ！森口。

(Kokuhaku 2010,01:11:48 - 01:12:12)

Yuko : Dua di antara susunya telah aku campurkan dengan sesuatu. Darah Sakuramiya sensei yang terinfeksi HIV.

Shuya : Cerdas sekali, Moriguchi!

Yuko mengatakan hal tersebut di dalam kelas, setelah semua siswa meminum susu dari sekolah. Shuya yang terkejut langsung melarikan diri ke toilet laki-laki di sekolahnya. Ketika sampai di toilet, ia malah tertawa terbahak-bahak setelah mendengar ucapan Yuko tersebut. Pada adegan ini, dapat terlihat bagaimana cara Shuya menarik diri dari kontak sosial. Shuya memilih untuk mengeluarkan emosinya di toilet, tempat yang sepi dan tidak ada orang di dalamnya. Adegan ini sangat menjadi fakta bahwa Shuya cenderung menarik diri dari kontak sosial. 


\subsubsection{Fungsi}

Sama seperti manusia pada umumnya, Shuya juga mempunyai 4 fungsi yang terlihat pada film Kokuhaku.

\section{a. Berpikir}

Orang berfungsi berpikir umumnya bekerja atas dasar logika, objektivitas, dan bermental analitis. Berikut merupakan adegan saat Shuya memperlihatkan fungsi berpikirnya.

1. Mereka yang memiliki fungsi berpikir kurang tertarik pada perasaan orang lain (Naisaban 2003: 27). Pada adegan ini, Shuya menceritakan tentang kematian Manami dengan tersenyum di hadapan Yuko.

悠子：A は意気揚々と真相を語りました。目の前にいるのが、自分が殺した 子の母親であることなど気にもしない様子で。

(Kokuhaku 2010,00:20:16-00:20:24)

Yuko : Siswa A menceritakannya sambil tersenyum. Seolah tak menyadari bahwa yang ada di hadapannya itu adalah ibu dari anak yang ia bunuh.

Shuya menceritakan mengenai kematian Manami sambil tersenyum. Padahal Shuya adalah dalang dibalik kematian Manami, dan Yuko adalah ibu dari Manami. Meski demikian, Shuya menceritakannya dengan terlihat seperti tanpa penyesalan tetapi justru dengan suka cita, karena rencananya telah berhasil. Sebagai seorang ibu yang anaknya telah dibunuh oleh Shuya, tentu saja Yuko merasa sakit hati. Tetapi, Shuya terlihat tidak tertarik akan hal itu, dia cenderung tidak peduli. Hal ini memperlihatkan fungsi berpikir pada Shuya yang mana kurang tertarik akan perasaan orang lain.

2. Naisaban menjelaskan (2003:27) bahwa mereka yang memiliki fungsiberpikir senang membuat analisis dan mengatur segala sesuatu dengan keadaan yang teratur.

Gambar 4.2.2

Scene Film Kokuhaku Memperlihatkan Shuya Merekam Rencananya

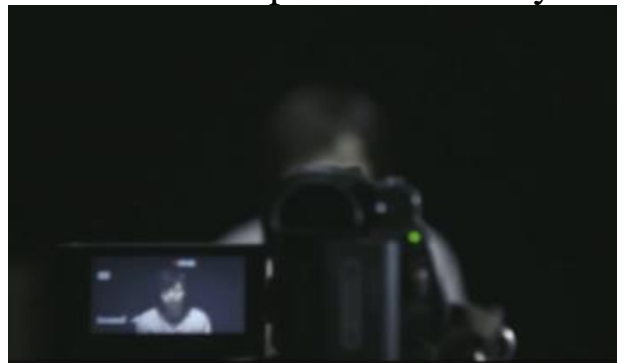

Sumber: Kokuhaku 2010, 01:03:44 
修哉：8月 31 日、さっき学校に爆弾を仕掛けた。スイッチは僕の携帯の発信 ボタンだ...読み終わると同時にスイッチを押す。

(Kokuhaku 2010,01:03:43-01:04:50)

Shuya : 31 Agustus. Aku meletakan sebuah bom di sekolah. Aku menghubungkannya dengan HP-ku...Aku akan meledakkannya setelah selesai berpidato.

Shuya merencanakan pengeboman di sekolahnya di hari dimana dia akan berpidato di depan seluruh warga sekolah. Ia telah merencanakan hal ini dari jauh hari, terlihat pada gambar 4.41 bahwa ia sedang merekam pengumumannya untuk dimuat dalam website miliknya. Alasannya untuk memuatnya di website karena ia tidak ingin orang berspekulasi mengenai kejadian tersebut. Tujuannya adalah agar orang mengetahui bahwa dirinyalah yang merencanakan pengeboman tersebut.

Caranya menyusun rencana dari merekam video, kemudian menaruh bom di sekolahnya yang telah dihubungkan ke telepon genggamnya, kemudian akan ia ledakan setelah selesai berpidato, sudah ia atur semuanya dengan teratur.

\subsection{Analisis Kepribadian Naoki Shimomura}

\subsubsection{Sikap}

Tokoh Naoki menunjukkan kedua sikap berdasarkan kepribadian Jung. Berikut penulis akan memaparkan data dari sikap tersebut.

\section{a. Introvert}

Pada film Kokuhaku, Naoki juga menunjukan sikap introvertnya. Berikut beberapa adegan yang menonjolkan sikap introvert tokoh Naoki.

1. Seorang introvert cenderung menarik diri dari kontak sosial. Menurut Jung (Naisaban 2003: 18), orang introvert memfokuskan libidonya ke dalam, dan tenggelam ke dalam diri sendiri, khususnya pada saat-saat mengalami tegangan dan tekanan batin.

Gambar 4.3.1

Scene Film Kokuhaku yang Memperlihatkan Naoki Menulis "Mati”

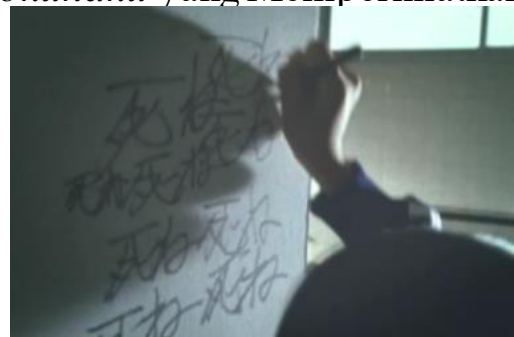

Sumber: Kokuhaku 2010, 00:21:27 
悠子：B は入学して運動部に入りましたが、練曶は体力づくりばかりで、ラ ケットさせ握らせてもらえません。Bは不満でしたが、顧問の先生に光 れを言う勇気などなく。

(Kokuhaku 2010,00:21:21 - 00:21:34)

Yuko : Siswa B mulai menekuni olahraga sejak masuk sekolah. Tapi dia hanya terus latihan tanpa pernah diijinkan untuk bermain. Dia merasa tidak senang tetapi tidak berani mengatakannya pada pelatihnya.

Siswa B yang diceritakan oleh Yuko adalah Naoki. Seperti yang dikatakan oleh Yuko, Naoki tidak berani mengatakan kehendaknya pada sang pelatih meskipun ia tidak menyukai hal itu. Naoki cenderung menarik diri dari dunia luar dan tenggelam pada dirinya sendiri, terbukti pada gambar yang terlihat di atas. Adegan itu memperlihatkan Naoki berkali-kali menuliskan kata "mati”, yang menyimpulkan bahwa dirinya sangat tertekan hingga ingin mati. Hal yang dilakukan oleh Naoki ini sangat mencerminkan sikap introvert, yaitu menarik diri dari kontak sosial karena dia bahkan tidak berani untuk berbicara kepada pelatihnya dan tenggelam pada dirinya sendiri hingga ingin mati karena merasa sangat tertekan.

2. Dalam kondisi kurang normal, orang introvert menjadi orang yang pesimis dan cemas (Naisaban 2003: 19). Naoki terlihat sangat pesimis dan cemas pada adegan berikut.

Gambar 4.3.1

Scene Film Kokuhaku yang Memperlihatkan Kecemasan Naoki

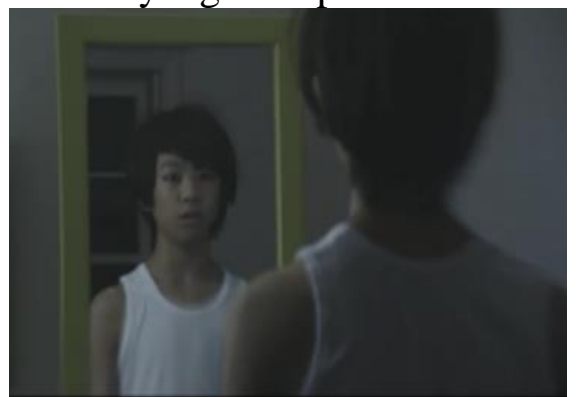

Sumber: Kokuhaku 2010, 01:14:27

直樹：僕は生きてるその実感が全然ない。くさい...でもこれが生きている証、 この歯も、この髪も、この爪も、このにおいも、おなかがすくのも、生 きている証。

(Kokuhaku 2010,01:14:05 - 01:14:18)

Naoki : Aku tidak merasa seperti masih hidup. Bau. Itu berarti aku masih hidup. Gigi, rambut, kuku, dan bauku. Aku masih merasakan lapar, itu berarti aku masih hidup. 
Gambar 4.4, Naoki terlihat sangat lusuh dan kotor, tetapi hal itulah yang menurutnya menandakan bahwa dirinya masih hidup. Setelah dibersihkan, ia mengira dirinya sudah mati, karena sudah tidak ada tanda kehidupan yaitu baunya, gigi dan rambutnya yang kotor. Keadaan tersebut memperlihatkan bagaimana Naoki merupakan seorang tokoh yang memiliki tingkat pesimis dan kecemasan yang tinggi.

\subsubsection{Fungsi}

Seperti kedua tokoh lainnya, Naoki juga mempunyai 4 fungsi jiwa yang ia tunjukkan di film Kokuhaku berdasarkan kepribadian Jung.

\section{a. Berpikir}

Orang berfungsi berpikir umumnya bekerja atas dasar logika, objektivitas, dan bermental analitis. Berikut yang membuktikan bahwa Naoki memiliki fungsi berpikir.

1. Mereka kadang menyakiti orang lain tanpa mereka sadari (Naisaban 2003: 27). Naoki telah menyakiti hati orang lain tanpa ia sadari pada adegan berikut ini.

Gambar 4.3.2

Scene Film Kokuhaku yang Memperlihatkan Kesedihan Ibu Naoki

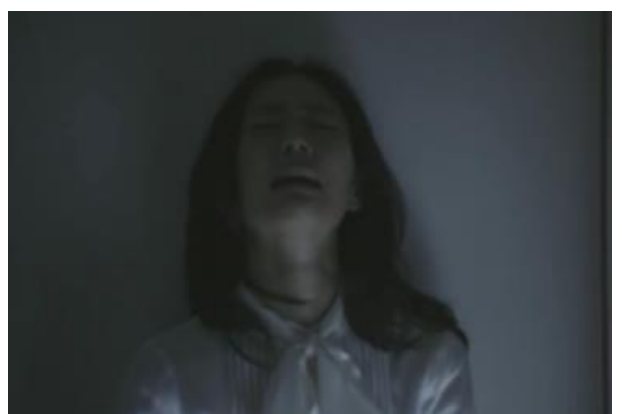

Sumber: Kokuhaku 2010, 00:36:50

直樹：わ〜〜〜余計なことしゃべんなよ、光のクソババ

下村優子：直くん！何もかも、あの女のせいだ！優しかった直樹が、こんなこ とに

(Kokuhaku 2010, 00:36:46 - 00:37:07)

Naoki : WA!!!! Aku bilang jangan menggangguku!!

Yuko : Ini semua adalah salah wanita itu. Naoki-ku tersayang menjadi seperti ini.

Gambar 4.3.2 diatas juga memperlihatkan bagaimana ekspresi ibu Naoki yang terlihat sedih dan sakit hati atas perbuatan Naoki. Naoki tentu saja melakukan itu semua; 
meneriaki dan mendorong ibunya, karena alasan yang ia anggap benar, tanpa menyadari bahwa hal itu menyakiti dan membuat ibunya sedih. Fungsi berpikirnya membuatnya seperti ini. Yaitu menyakiti orang lain tanpa mereka sadari karena dirinyaterlalu fokus pada logika dan pikirannya sendiri.

2. Orang berfungsi pemikir pada umumnya bekerja atas dasar logika (Naisaban, 2003: 27). Adegan berikut ini menggambarkan bagaimana tokoh Naoki bekerja atas dasar logikanya.

直樹：食べないほうがいいよ。エイズになっちゃうから。

(Kokuhaku 2010,00:52:24-00:52:27)

Naoki : Sebaiknya jangan memakannya, nanti ibu tertular AIDS.

Kutipan di atas diucapkan Naoki kepada ibunya saat ibunya akan memakan makanan yang kemasannya sudah dipenuhi oleh darah Naoki. Naoki menggunakan logikanya bahwa ibunya akan tertular AIDS apabila menyentuh darahnya, oleh karena itu ia melarang ibunya untuk memakan makanan tersebut. Adegan ini mencerminkan bagaimana tokoh Naoki bertindak atas dasar logikanya untuk menyelamatkan ibunya dari penyakit AIDS. Karena Naoki berpikir bahwa dirinya telah terkontaminasi oleh penyakit tersebut.

\subsection{Tipologi Kepribadian Tokoh}

Setelah penulis melakukan analisis mengenai kepribadian dari masing-masing tokoh pelaku pembunuhan pada film Kokuhaku, dapat ditarik rangkuman mengenai tipologi kepribadian para tokoh pada tabel di bawah ini.

Tabel 4.4 Rangkuman Tipologi Kepribadian Tokoh Pelaku Pembunuhan

\begin{tabular}{|c|l|l|l|l|}
\hline No. & \multicolumn{1}{|c|}{ Tokoh } & Sikap & Fungsi & Tipologi Kepribadian \\
\hline 1 & Yuko Moriguchi & Ekstrovert & Berpikir & Ekstrovert-Berpikir \\
\hline 2 & Shuya Watanabe & Introvert & Berpikir & Introvert-Berpikir \\
\hline 3 & Naoki Shimomura & Introvert & Berpikir & Introvert-Berpikir \\
\hline
\end{tabular}

Tokoh Yuko memiliki sikap ekstrovert dan fungsi berpikir, dengan ini tipologi kepribadiannya menjadi ekstrovert-berpikir. Hal ini dapat dilihat dari analisis sebelumnya yang mana tokoh Yuko merupakan individu yang berprinsip akan kenyataan objektif, kemudian ia cenderung menekan fungsi perasanya dan bekerja atas dasar logika. 
Kemudian tokoh Shuya memiliki sikap introvert dan fungsi berpikir, sehingga tipolgi kepdibadiannya adalah introvert-berpikir. Dapat dilihat dari analisis penulis bahwa tokoh Shuya merupakan tokoh penyendiri yang menarik diri dari kontak sosial serta kurang memikirkan perasaan orang lain sehingga cenderung menyakiti orang lain.

Tokoh terakhir yang penulis analisis kepribadiannya adalah Naoki. Naoki memiliki sikap dominan introvert dengan fungsi berpikir, maka tipologi kepribadian Naoki adalah introvert-berpikir.Terlihat dari bagaimana tokoh Naoki merupakan individu yang penyendiri senang memutuskan keputusannya sendiri tanpa memperhatikan keinginan dari orang lain.

\subsection{Analisi Ikigai Tokoh}

Hasegawa mengartikan ikigai sebagai perasaan dari menjalani kehidupan yang sekarang dan juga kesadaran individu sebagai motivasi untuk hidup. Pada sub-bab ini, penulis akan menganalisis ikigai para tokoh pelaku pembunuhan.

\subsubsection{Ikigai Yuko Moriguchi}

Pada film Kokuhaku, Yuko merupakan salah satu tokoh yang melakukan pembunuhan. Pada beberapa adegan berikut ini, dapat terlihat ikigai dari tokoh Yuko.

修哉：僕なら殺すアイテムなら、ほら、全部自分の手で作り出せるんだ。 悠子：殺してやりたい！关のとき、私は本気で龹う思いました。 (Kokuhaku 2010,00:20:57-00:21:16)

Shuya : Jika aku ingin membunuh seseorang, aku akan menggunakan alat buatanku sendiri.

Yuko : Aku ingin membunuhnya. Itulah yang ada dalam pikiranku saat itu.

Kutipan di atas terjadi saat Shuya menceritakan mengenai pembunuhan Manami yang ia lakukan bersama dengan Naoki. Dengan bangga Shuya mengatakan di depan Yuko yang mana adalah ibu dari Manami, bahwa ia membunuh menggunakan alat yang ia buat sendiri. Setelah Shuya berkata seperti itu, yang ada pada pikiran Yuko adalah bahwa ia ingin membunuh Shuyasebagai balasan akan perbuatannya yang telah mengambil nyawa Manami.

悠子: これが私の復售です。ほんとの地獄。ここから、あなたの更生の第一歩 が始まるんです

(Kokuhaku 2010,01:42:26-01:42:56) 
Yuko : Ini adalah pembalasan dendamku. Neraka sesungguhnya. Ini adalah awal dari penderitaan yang akan kau alami.

Berdasarkan kutipan tersebut, terlihat bahwa Yuko masih akan melakukan banyak hal yang akan membuat Shuya menderita. Hal ini menandakan bahwa kedepannya, rencana dalam hidup Yuko adalah untuk membuat Shuya merasa menderita. Jika disimpulkan makan ikigai dari tokoh Yuko dalam film Kokuhaku adalah anaknya, Manami. Terlihat dari bagaimana Yuko yang merasa sangat kehilangan Manami, dan rela melakukan semuanya demi kesejahteraan hidup Manami.

\subsubsection{Ikigai Shuya Watanabe}

Tokoh Shuya merupakan salah satu tokoh utamayang mendapatkan screen time paling banyak di film Kokuhaku. Beberapa adegan yang akan penulis analisis ini menggambarkan ikigai dari tokoh Shuya.

悠子：Aの殺人の動機は馬鹿馬鹿しいほど単純で、自分の才能を世間に認めさ せたい。誰よりも優秀な人間として注目されない。しかし、工作展に入 賞した Aの記事が新聞に乗せた日、世間の注目を浴びたのは A ではなく、 同じ 13 歳の少女...

(Kokuhaku 2010,00:20:27 - 00:20:52)

Yuko : Motif siswa A membunuh benar-benar tidak masuk akal. Dia ingin diakui oleh dunia. Dia ingin diakui sebagai anak yang jenius. Tapi saat berita tentang kemenangannya dimuat di koran, bukan dia yang menjadi bahan perhatian. Melainkan anak lain yang merupakan gadis berusia 13 tahun...

Awalnya, ia mencoba untuk mendapatkan perhatian dari ibunya dengan hal-hal yang positif, yaitu menciptakan penemuan-penemuan sains hingga mengikuti kompetisi sains yang berhasil ia menangkan dengan membawa pulang hadiah juara satu. Tetapi itu semua tidak mendapatkan perhatian dari dunia, khususnya ibunya. Hingga akhirnya ia mengunggah hal-hal aneh di website-nya, seperti mesin eksekusi binatang, dan diluar perkiraannya, hal tersebut justru mendapatkan banyak perhatian dan website-nya mulai lama dikunjungi orang. Berangkat dari hal tersebut, akhirnya ia merencanakan kasus pembunuhan menggunakan alat buatannya sendiri.

修哉:こんなじゃ、世間は少しも騒がない、誰も母だって気づいてくれないも っと大きく、全マスコミが取り扱うすごい事件...殺人。

(Kokuhaku 2010,01:08:27-01:08:43) 
Shuya : Kemenanganku tidak mendapat perhatian. Tidak dari seorangpun, khususnya dari ibuku. Aku harus melakukan sesuatu untuk menarik perhatian media. Sebuah kasus besar. Pembunuhan.

Ide Shuya tersebut muncul karena dirinya sudah sangat putus asa karena semua usahanya tidak kunjung mendapatkan apa yang ia inginkan, yaitu pengakuan dari dunia dan kembalinya ibunya ke hidupnya. Akhirnya Shuya memilih untuk melakukan pembunuhan yang jenius dengan alat yang memenangkan kompetisi sains itu. Dari sini, Shuya mengajak Naoki untuk masuk dan bekerjasama untuk melaksanakan misinya hanya sebagai kaki tangannya. Shuya ingin ibunya mengetahui kejeniusannya dan kembali kepadanya untuk memberikan perhatian yang ia inginkan.

Berdasarkan analisis di atas, simpulannya menunjukkan bahwa mendapatkan pengakuan dari ibunya akan kejeniusannya merupakan motivasi tokoh Shuya untuk terbangun dan menjalani hidup setiap harinya. Walaupun caranya dengan merenggut nyawa orang lain, tetapi Shuya tetap melakukan apapun yang menurutnya adalah hal yang tepat demi mendapatkan pengakuan dari kepintarannya dan mendapatkan kembali kasih sayang dari ibunya. Hal tersebut merupakan ikigai dari tokoh Shuya di film Kokuhaku. Shuya merasa bahwa hidupnya akan bahagia jika mendapatkan semua hal itu, maka ia melakukan segala cara hanya untuk mencapai pengakuan dan kasih sayang tersebut.

\subsubsection{Ikigai Naoki Shimomura}

Dalam film Kokuhaku, tokoh Naoki digambarkan sebagai sosok anak SMP yang mempunyai banyak ketakutan, terutama pada adegan berikut ini.

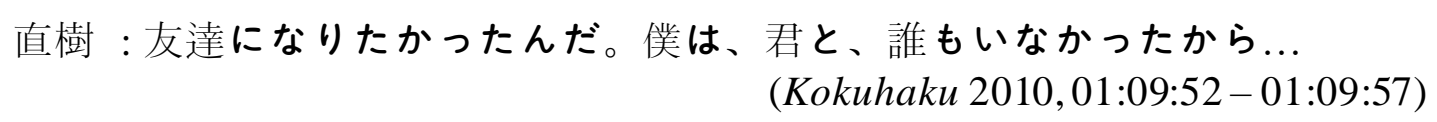

Naoki: Aku ingin menjadi temanmu. Hanya kaulah temanku, aku tidak memiliki teman.

Kutipan di atas menunjukkan bagaimana tokoh Naoki sangat menginginkan keberadaan Shuya sebagai temannya Saat menceritakan bagian ini, Naoki terlihat meneteskan air matanya. Hal ini membuktikan seberapa penting tokoh Shuya yang datang kepada Naoki untuk mengajaknya berteman. 
Gambar 4.5.3

Scene Film Kokuhaku yang Memperlihatkan Kesenangan Naoki Dihampiri Shuya

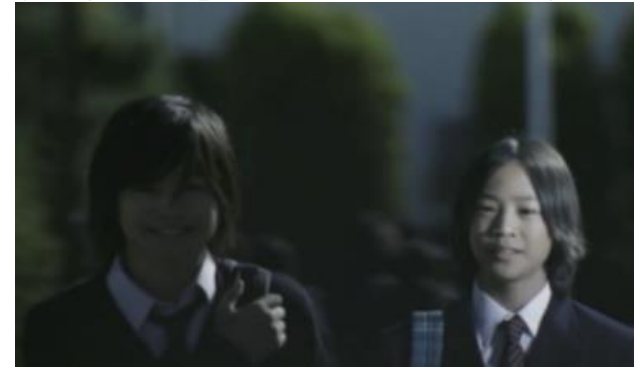

Sumber: Kokuhaku 2010, 01:10:15

修哉：一緒にビデオでも見ない？前から君と話してみたかったんだ。

直樹：こんな僕を気にするやつなんか...

修哉:君は他のバカたちとは違う、なんだか余裕があって大人で...

直樹: こんな僕を認めてくれるやつなんか、だから君に言われたとおり、僕が ターゲットを決めて!

(Kokuhaku 2010,01:10:01 - 01:10:20)

Shuya: Apa kau mau menonton video bersama? Sudah lama aku ingin menyapamu.

Naoki: Tidak ada yang pernah memperhatikanku...

Shuya: Kau sepertiny a berbeda dari para orang bodohitu. Kau terlihat kalem dan dewasa. Naoki : Akhirnya aku diakui oleh seseorang. Jadi aku memilih korban untukmu.

Gambar di atas adalah adegan ketika Shuya mengajak Naoki untuk berteman. Terlihat bagaimana Naoki mengembangkan senyumnya dan terlihat bahagia. Dari cuplikan dialog di atas diketahui bahwa Naoki bahkan memilih orang yang akan ditargetkan Shuya untuk mencoba alat penemuannya yaitu dompet anti copet, yang mana merupakan awal dari konflik besar dalam film ini. Tetapi kemudian ia dikecewakan karena fakta bahwa Shuya membunuh hanya untuk mendapatkan perhatian dari orang lain. Tetapi, ternyata Shuya gagal membunuh dengan alatnya karena Manami hanya pingsan.

修哉：君は出来損ないだよ。

直樹：出来損ない?あいつは殺す気だった、なのに殺せなかった。あいつこ光 出来損ないだ！ざまあみろ！僕はあいつができなかったことをやり逐げ たんだ !

(Kokuhaku 2010, 01:10:54 - 01:46:35)

Shuya: Kau orang yang tidak berguna.

Naoki : Tidak berguna? Dia ingin membunuh tapi gagal. Dialah yang tidak berguna! Sialan! Aku berhasil melakukan apa yang gagal dia lakukan. 
Akibat dari Shuya yang mengatakan bahwa Naoki tidak berguna, Naoki merasakan kekecewaan yang besar. Maka dari itu, ketika mengetahui bahwa Shuya gagal dalam membunuh Manami, Naoki kemudian melempar tubuh Manami ke dalam kolam ranang. Naoki melakukan hal tersebut agar Shuya mengetahui bahwa ia berguna, dan bisa melakukan suatu hal yang Shuya tidak bisa.

Berdasarkan data-data di atas, maka dapat terlihat bahwa Naoki membunuh Manami karena ia ingin Shuya melihatnya sebagai teman yang berguna. Naoki juga ingin mendapatkan pengakuan dari Shuya. Maka dapat disimpulkan bahwa ikigai dari tokoh Naoki adalah mendapatkan pengakuan. Karena Naoki merasa senang ketika keberadaannya diakui oleh seseorang.

\subsection{Hubungan Antara Kepribadian dan Ikigai Tokoh Pelaku Pembunuhan}

Pada sub-bab sebelumnya, penulis telah menganalisis mengenai kepribadian dan ikigai masing-masing tokoh pelaku pembunuhan. Kepribadian dari masing-masing tokoh mempengaruhi ikigai dan caranya menghadapi masalah-masalah dalam hidup. Pada subbab ini, penulis akan menganalisis hubungan antara kepribadian dan ikigai tokoh berdasarkan hasil analisis sebelumnya.

\subsubsection{Hubungan Antara Kepribadian dan Ikigai Tokoh Yuko Moriguchi}

Tokoh Yuko Moriguchi pada film Kokuhaku memiliki sikap dominan ekstrovert dan fungsi dominan berpikir, sehingga tipologi kepribadiannya adalah ekstrovert-berpikir. Hal ini menjadikan Yuko sebagai tokoh Yuko yang berani, juga memiliki prinsip yang kuat akan kenyataan objektif, kemudian Yuko cenderung menekan fungsi perasanya dan lebih bekerja atas dasar logikanya menyebabkan tokohnya menjadi individu yang kurang emosional.

Sikap ekstrovert yang dimiliki oleh Yuko menyebabkan dirinya mempunyai keterikatan dengan orang lain, dalam hal ini adalah Manami, anaknya. Yuko bahkan lebih memikirkan Manami daripada dirinya sendiri. Hal tersebut juga yang menjadi alasan bahwa ikigai dari tokoh Yuko adalah anaknya. Pada film Kokuhaku, anaknya menjadi korban pembunuhan kedua muridnya sendiri, yaitu Shuya dan Naoki. Maka ketika ikigainya direnggut oleh orang lain, fungsi berpikirnya mempengaruhi perbuatannya. 
Fungsi dominan berpikir pada tokoh Yuko dalam film Kokuhaku membuat tokoh tersebut menekan fungsi perasany a dan bertindak atas das ar logika sehingga menjadi kurang emosional. Yuko cenderung tidak memikirkan perasaan orang lain dan tetap mengandalkan prinsipnya sendiri, yaitu harus membuat Shuya dan Naoki merasakan penderitaan seperti yang dia rasakan karena telah membunuh anaknya yang menjadi ikigai-nya.

\subsubsection{Hubungan Antara Kepribadian dan Ikigai Tokoh Shuya Watanabe}

Pada film Kokuhaku tokoh Shuyamempunya sikap dominan introvert danfungsi dominan berpikir, maka tipologi kepribadiannya adalah introvert-berpikir. Kepribadiannya tersebut membuat Shuya menjadi tokoh yang penyendiri dan menarik diri dari kontak sosial serta kurang memikirkan perasaan orang lain sehingga cenderung menyakiti orang lain.

Sikap introvert Shuya membuatnya menjadi tokoh yang penyendiri dan hanya memikirkan dirinya sendiri. Hal ini mempengaruhi ikigai-nya yaitu mendapatkan pengakuan demi kepuasan dirinya sendiri. Shuya ingin mendapatkan pengakuan atas kejeniusannya menggunakan caranya sendiri yang ia anggap benar, yaitu membunuh orang lain. Meskipun ikigai merupakan sesuatu yang positif, tetapi dalam penelitian terdahulu yang dilakukan oleh Kano dan Walker membuktikan bahwa ikigai bisa mengarah ke hal yang negatif akibat stres yang ditimbulkan karena harus berinteraksi dengan orang lain. Pada film Kokuhaku, Shuya merupakan tokoh introvert yang lebih senang menyendiri, tetapi ikigai-nya menyebabkan dirinya ada dalam interaksi sosial demi mencapai ikigainya yaitu mendapatkan pengakuan dari orang lain, khususnya dari ibunya.

Fungsi berpikirnya juga mempengaruhinya tindakannya untuk melakukan pembunuhan demi tercapainya ikigai yang dimiliki. Shuya hanya berpikir atas dasar logika tanpa memikirkan perasaan orang lain. Shuya mengajak Naoki untuk bekerjasama dalam pembunuhan Manami tanpa memikirkan perasaan dari Yuko. Rencananya dalam melakukan pembunuhan juga sangatlah rapi dan terstruktur, hal ini dikarenakan mereka yeng dominan fungsi berpikir cenderung mengatur segala sesuatu dengan teratur.

\subsubsection{Hubungan Antara Kepribadian dan Ikigai Tokoh Naoki Shimomura}

Naoki dalam film Kokuhaku memiliki sikap introvert dan fungsi berpikir, sehingga tipologi kepribadiannya adalah introvert-berpikir. Kepribadiannya ini menjadikan Naoki 
sebagai tokoh yang penyendiri dan cenderung lebih senang memutuskan tindakannyaatas keputusannya sendiri tanpa memperhatikan keinginan dari orang lain.

Pada film Kokuhaku, Naoki membunuh Manami hanya untuk mencapai ikigai-nya yaitu mendapatkan pengakuan dari Shuya bahwa dirinya bisa menjadi teman yang berguna. Karena sebelumnya Naoki merupakan tokoh yang tidak memiliki teman, sehingga ketika Shuya mengajaknya berteman, dirinya merasa senang dan rela melakukan apapun agar mendapatkan pengakuan dari Shuya yang sudah menjadi temannya.

Tindakannya dalam membunuh untuk mencapai ikigai-nya juga dipengaruhi oleh fungsi berpikirnya. Karena Naoki hanya mengandalkan logikanya dalam bertindak dan tidak mempedulikan perasaan orang lain sehingga perbuatannya dapat menyakiti orang lain tanpa disadari. Walaupun ikigai adalah hal yang positif, tetapi sama seperti Shuya, Naoki mengarahkan energinya menuju hal negatif untuk mencapai ikigai-nya.

\section{Simpulan}

Hasil dari analisis penulis mengenai tipologi kepribadian para tokoh pelaku pembunuhan, ditemukan bahwa tipologi kepribadian tokoh Yuko adalah ekstrovertberpikir. Kemudian tokoh Shuya Watanabe memiliki sikap introvert dan fungsi berpikir, sehingga tipolgi kepdibadiannya adalah introvert-berpikir. Terakhir adalah Naoki Shimomura. Naoki memiliki sikap dominan introvert dengan fungsi berpikir, maka tipologi kepribadian Naoki adalah introvert-berpikir. Selanjutnya, penulis melakukan analisis terhadap ikigai tokoh pelaku pembunuhan. Tokoh pertama Yuko Moriguchi memiliki Manami atau anaknya sebagai ikigai-nya. Kemudian Shuya Watanabe dan Naoki Shimomura yang mempunyai ikigai yang serupa, yaitu mendapatkan pengakuan akan diri mereka dari orang lain. Setelah itu, ditemukan bahwa terdapat hubungan antara kepribadian dan ikigai para tokoh pelaku pembunuhan pada film Kokuhaku. Karena baik kepribadian dan ikigai para tokoh saling berkesinambungan dan mempengaruhi satu sama lain khususnya pada perilaku yang dilakukan.

\section{Daftar Pustaka}

Az-Zuhaili, Wahbah. (1984). Fiqih Islam wa Adillatuhu. Jilid 7. Bairut: Darul Fikr. 
Kono, Shintaro dan Walker, Gordnon. (2020). "Theorizing The Interpersonal Aspect of Ikigai ('Life Worth Living') Among Japanese University Students: A Mixed-methods Approach". International Journal of Wellbeing, 10(2), hlm. 19

Kristanto, JB. (2004). Nonton Film Nonton Indonesia. Jakarta: Penerbit Buku Kompas. Miles, B. Mathew dan Michael Huberman. (1992). Analisis Data Kualitatif Buku Sumber Tentang Metode-metode Baru. Jakarta: UIP.

Mitsuhashi, Yukari. (2018). Ikigai: Giving Every Day Meaning And Joy. London: Kyle Books.

Musman, Asti.(2020). The Power of Ikigai. Yogyakarta: Anak Hebat Indonesia.

Naisaban, Ladislaus. (2003). Psikologi Jung: Tipe Kepribadian Manusia dan Rahasia Sukses dalam Hidup (Tipe Kebijaksanaan Jung). Jakarta: PT. Grasindo.

Rivai, Veithzal. (2016). Manajemen Sumber Daya Manusia Untuk Perusahaan. Jakarta: PT. Raja Grafindo Persada.

Sobur, Alex. (2003). Psikologi Umum. Bandung: Pustaka Setia. 